\title{
Public Sector Motivation and Development
}

\section{Failures}

\author{
Rocco Macchiavello*
}

December 2003

\begin{abstract}
This paper provides a theoretical analysis of the relationship between public sector motivation and development. The main implication derived from the model is that, somewhat paradoxically, it is not necessarily a good thing to have cheap labor to hire in the bureaucracy. Cheap labor makes it more difficult to screen honest individuals. Moreover, motivated agents are not sufficient to prevent corruption. The literature recognizes that a good public service can be obtained only with sufficient pecuniary incentives or personnel motivation. While empirical evidence exists casting some doubt on the first view, this paper shows that the latter one may not be sufficient.
\end{abstract}

Keywords: Public Sector Motivation, Institutions, Development, Corruption, Multiple Equilibria

JEL Codes: D73, H10, O11, P49.

${ }^{*}$ Paris-Jourdan (Delta) and LSE-STICERD. I am particularly indebted to Francois Bourguignon and Maitreesh Ghatak for their advice and encouragement. I also thank Tim Besley, Mike Elsby, Thomas Piketty, Andrea Prat, Thierry Verdier and seminar participants at LSE and at the LACEA workshop in Political Economy for helpful comments. All errors are mine. Correspondence: London School of Economics and Political Science, Sticerd, Houghton Street WC2A 2AE, London UK. E-Mail: R.Macchiavello@lse.ac.uk. 


\section{Introduction}

Understanding the role played by the state in fostering economic growth and development is a crucial question for economists (see e.g. Amsden (1989), Wade (1990) and Evans (1998)). Much attention has been paid to the study of the determinants of corruption (Treisman (2000)), its effects on economic performance (Mauro (1995)) and the organizational features associated with a high quality public service (Evans and Rauch (1999, 2000). The World Development Report (WorldBank (1997)), for instance, paid attention principally to the provision of incentives on the job (according to standard efficiency wage arguments) and to the selection of talented people (motivated agents would automatically be attracted by meritocratic recruitment). On the other hand, empirical evidence shows that the wage premium in the public sector is not a good predictor of the level of corruption, that there is huge cross country dispersion in public sector wage premia, and that cultural and historical variables seem to play an important role. Lastly, no precise channel has been identified to explain how the level of development affects the level of corruption and public sector quality ${ }^{1}$.

This paper, emphasizing a joint analysis of public sector bureaucracies

\footnotetext{
${ }^{1}$ Leaving aside the standard argument that richer countries can afford higher wages discouraging corruption for public servants, which is not however supported by strong empirical evidence.
} 
and economic performance, takes a different perspective. While public service motivation (PSM) frequently appears in sociological and administrative studies of public bureaucracies, it has been highly disregarded by economists $^{2}$. In this non economic literature, differences in (incentives based) payment between public and private sector managers are thought to be compensated by a non-pecuniary benefit for the public employees. Along these lines, in Wilson (1989) public sector agencies are built around the idea of "mission". The mission of a public sector agency is identified with the culture embedded in the preferences of its boss. This process of identification with the mission often motivates agents to perform their tasks more effectively than monetary incentives. The comparative study on IT-sector policies in three developing countries in Evans (1998) provides a good example of how PSM agents can positively impact the functioning of state bureaucracy. Writing about the Department of Electronics in India, Evans reports that this agency "had always been dominated by technically oriented managers with a strong substantive interest in the sector for which they were responsible... DOE technocrats were immersed in a project of transformation that was of greater interest than minor individual perquisites".

\footnotetext{
${ }^{2}$ Rainey and Steinbauer (1999) quoted in Francois (2000), define it as a "general, altruistic motivation to serve the interests of a community of people, a state, a nation, or humankind...".
} 
He reports similar experiences for the Commission for the Coordination of Electronic Processing Activities (CAPRE) in Brazil, and for the equivalent agency in Korea. Wade (1989) reports similar evidence for top economic bureaucracies in Taiwan. Among economists, Francois (2000) emphasizes that the public sector can indeed be more effective in exploiting the public service motivation of employees and can therefore be more efficient in the provision of public good. Besley and Ghatak (2003) present a model emphasizing the role of matching between principals and agents with similar preferred missions as an important source of efficiency in mission oriented organizations. Hart and Holmstrom (2003) present a model of firm scope in which the preferences of the boss may be specific to a particular activity. By choosing the appropriate manager, shareholders can commit to firm activities that increase the motivation and welfare of workers and reduce the wage bill for the firm.

I will follow this emerging literature by modelling PSM as an exogenous non monetary payoff that employees receive by working in the public sector. The mechanism of the model being general, it is presented in the context of a text-book model of moral hazard based on heterogeneity. The main model is then an application of this mechanism to the analysis of the relationship between public service motivation and development. In what follows I will 
often refer to corruption, but it should be kept in mind that the model can be reinterpreted in terms of shirking in the public sector. The interpretation in terms of corruption is somewhat closer to the cross country empirical literature.

The basic intuition goes as follows: suppose a bureaucracy is composed only by highly motivated agents and is such that wages in the bureaucracy are (below those prevailing in the private sector, but still) high enough to deter corruption. This will generate relatively efficient state intervention and high returns in the private sector. It will thus be easier to attract only non motivated applicants in the bureaucracy, justifying the initial assumption that the bureaucracy is of high quality. It is easy to construct the opposite vicious circle leading to low wages in the private sector and poor bureaucratic performance. This intuition thus suggests that multiple equilibria can exist for a given level of compensation in the public sector.

The model also predicts that the relationship between public sector wages and corruption may be non-monotonic. This result follows from the interplay of moral hazard and selection constraints, the latter working through the endogenously determined outside option for the public sector, i.e. the equilibrium wage in the private sector.

Because the main mechanism works through a self selection constraint, 
the multiple equilibria of the model are Pareto Ranked. The results can thus be reinterpreted as arising from a pure coordination failure. If non motivated agents believe that other non motivated agents will join the public sector in order to extract rents, they will find optimal to join the public sector too. This is so because the low quality of the public good worsens their position in the labor market. When rents that can be extracted from corruption are endogeneized, the Pareto ranking result is easily lost.

The main implication derived from the model is that, somewhat paradoxically, it is not necessarily a good thing to have cheap labor to hire in the public sector. Cheap labor, makes it more difficult to screen honest (publicly motivated) individuals. Moreover, motivated agents are not sufficient to prevent corruption. The literature recognizes that a good public service can be obtained only with sufficient pecuniary incentives or personnel motivation. While empirical evidence exists casting some doubts on the first view, this paper shows that the latter one may not be sufficient. In order to isolate in the most transparent way the economic mechanism behind the results, the analysis will treat variables that are likely determined by some form of political process as exogenous. Their endogeneization is discussed after the main results have been presented.

The rest of the paper is organized as follows. Section 2 presents the 
general argument with a simple model based on moral hazard, heterogeneity and complementarities. Section 3 considers an application of the general mechanism to the relationship between public sector motivation and development. The main results are presented, along with some extensions. Section 4 presents empirical evidence consistent with the main results, and further discusses some of the assumptions and policy implications. Section 5 offers some concluding remarks. All the proofs are in the Appendix.

\section{General Argument}

Assume two sectors, $i \in\{1,2\}$. There are two types of agents, $t \in\{\theta, 0\}$ in proportion $\alpha$ and $1-\alpha$ respectively. Both types, $t=0$ and $t=\theta>0$ can undertake two levels of effort, $e_{i, L}$ at zero utility cost and $e_{i, H}$ with associated disutility cost of $e_{i}-\Gamma(i) \cdot t$, where $\Gamma(i)$ is an indicator variable that takes value 1 in sector 1 and zero otherwise $\mathrm{e}^{3}$. Denote $y_{2}\left(e_{1}\right)$ the successful outcome in sector 2 , which is increasing in $e_{1}$, the average level of effort taken in sector 1. Assume however that $y_{1}\left(e_{2}\right)=y$ does not depend on $e_{2}$, the average level of effort in sector two. When a project fails it yields a payoff of zero in both sectors.

\footnotetext{
${ }^{3}$ This is equivalent to saying that high effort is less costly in sector 1 for $\theta$-type agents. All the other effort levels have the same cost for the two types of agents.
} 
In each sector there is free entry of principals with reservation utility equal to $\pi_{i} \geq 0$. Conditional on high effort, a project is a success with probability $\bar{p}_{i}=p_{i}>\frac{1}{2}$ If a worker chooses to exert no effort, at a cost $e_{i, L}=0$ the probability of a success is $\underline{p}_{i}=\frac{1}{2}<\bar{p}_{i}=p_{i}$. I will denote $\Delta p_{i}=p_{i}-\frac{1}{2}$. Workers are risk neutral and subject to a limited liability constraint: in each state of the world their compensation $w_{i, k}$, for $k \in\{l, h\}$ must be at least equal to zero

\section{Lemma 1}

If $\Delta p_{i} y_{i}\left(e_{j}\right) \geq \frac{\Delta p_{i} \pi_{i}}{p_{i}}+e_{i, H}$ the contracts in sector $i$ will implement the high level of effort.

When $e_{1}>\Delta p_{1}\left(y_{1}-\frac{\pi_{1}}{p_{1}}\right) \geq e_{1}-\theta$ it is thus the case that in sector $1 \theta$-type agents will exert high effort while $0-$ type agents will not. The two types will take different actions in sector 1 . Denote $U_{2}\left(e_{1}\right)$ the level of utility that agents receive in sector 2 . We thus have that either $U_{2}\left(e_{1}\right)=$ $p_{2} y_{2}\left(e_{1}\right)-e_{2}-\pi_{2}$ if $\Delta p_{2} y_{2}\left(e_{1}\right) \geq e_{2}+\frac{\Delta p_{2} \pi_{2}}{p_{2}}$ or $U_{2}\left(e_{1}\right)=\frac{1}{2} y_{2}\left(e_{1}\right)-\pi_{2}$ otherwise. $U_{2}\left(e_{1}\right)$ is increasing in $y_{2}\left(e_{1}\right)$, and thus in $e_{1}$ itself, and does not depend on agent's type.

Assuming for simplicity $\pi_{2}=0$, and $p_{2}\left(y_{2}\left(\frac{1}{2}\right)-\frac{e_{2}}{\Delta p_{2}}\right)>0$, we can state the following 


\section{Proposition 1}

When $e_{1}>\Delta p_{1}\left(y_{1}-\frac{\pi_{1}}{p_{1}}\right) \geq e_{1}-\theta$, and $p_{1} y_{1}-e_{1}-\pi_{1}+\theta>p_{2} y_{2}\left(p_{1}\right)-$ $e_{2}>\frac{1}{2} y_{1}-\pi_{1}>p_{2} y_{2}\left(\frac{1}{2}(1-\alpha)+\alpha p_{1}\right)-e_{2}$, there are 3 equilibria, in which 0 -type agents choose to work in sector 1 with probabilities equal to zero, one or $\widetilde{\alpha} \in(0,1)$. This last equilibrium is however unstable.

The intuition for the proposition goes as follows. Suppose only type $t=\theta$ works in sector one. Then effort will be high, and the utility of working in sector 2 will also be high: while $\theta$-type workers prefer sector 1 (first inequality), types $t=0$ will work in sector 2 (second inequality), and complete separation occurs. Conversely, suppose that types $t=0$ work in sector 1 . Then effort in sector 1 will be relatively low (on average equal to $\left.\widetilde{p}=p_{1} \alpha+\frac{1}{2}(1-\alpha)\right)$, and the utility from working in sector 2 will be lower (third inequality). This will in turn confirm that it is optimal for 0 -type workers to choose sector 1 , and a pooling equilibrium occurs ${ }^{4}$. In other terms, there is a strategic complementarity in the occupational choice decision. In this sense heterogeneity is crucial to obtain multiple equilibria.

Moreover, from the inspection of the condition above, we can also state the following

\footnotetext{
${ }^{4}$ When there is semi-pooling of types, the mixing in sector 1 is such that the utility of $0-$ types is the same in both sectors, so that they are indifferent and randomize with the "right" probabilities across the two occupations.
} 


\section{Corollary}

The two equilibria are Pareto Ranked.

The two equilibria are Pareto ranked because the mechanism works through a selection constraint. In particular it has to be the case that 0 -type workers are better off in sector 2 when $e_{1}=e_{H}$ than in sector 1 exerting no effort. This is the separating condition which defines the equilibrium itself.

Two remarks are important. From what is reported above it should be clear that not even the moral hazard component is necessary for the result: what is necessary is that heterogeneity changes the behavior in the sector exerting externalities on the other one. So far I have looked at heterogeneity on the cost of effort. It is possible to get similar results allowing heterogeneity in the productivity of effort (e.g. $p_{\theta}>p_{0}$ ) or on the (marginal) utility of money, or considering a continuous distribution of agent types ${ }^{5}$. Although the argument is presented through a simple example, the reasoning is thus general and robust to different types of heterogeneity.

\footnotetext{
${ }^{5}$ The mechanism is similar to the one in Ghatak et al. (2003) in the context of the interaction between labor and credit markets.
} 


\section{The model}

\section{$3.1 \quad$ Set Up}

Consider an economy composed of a private and a public sector. Variables related to the latter will have a $b$-subscript, while the former a $p$-subscript. Returns in the private sector are positively affected by the quality of a public good provided by the public sector bureaucracy. Infrastructures and law enforcement are common examples of this sort of public good. In general, one may think of these public goods as the quality of Governance of the country.

The economy is populated by a continuum of measure one of individuals that live only one period. The public sector is of size $b$, which is assumed to be exogenously given and determined by an unspecified political economy process. Individuals are heterogeneous in terms of a characteristic referred to as public service motivation. The way public service motivation affects utility and (equilibrium) behavior of agents will be specified later. The proportion of motivated agents in the economy is $\alpha>b^{6}$.

\footnotetext{
${ }^{6}$ It will become clear that if $\alpha<b$ there are not enough motivated agents to fill the public sector. It would not be possible to solve the selection problem in the public sector, and an underdevelopment trap would be automatically obtained.
} 


\subsection{Agency problem in the public and private sector}

Each public sector employee controls an exogenously given amount of resources $g$ that she can partially divert to increase her payoff by an amount equal to $\rho g$, with $\rho \leq 1$. If she is caught (which occurs with exogenously given probability $q$ ), she loses her job, and wage. This is assumed to be the maximum penalty available to deter public sector employees against corruption. A motivated agent simply receives an extra non monetary payoff $\theta$ by working in the public sector; this extra non monetary payoff thus has the effect of favoring deterrence of corruption ${ }^{7}$. Even motivated agents will yield to temptation, if temptation is strong enough. Denoting $w^{b}$ the (exogenously given) wage paid in the public sector, we can define the value of a public sector career as $V^{b}\left(w^{b}, \theta\right)=\max \left\{w^{b}+\iota(\theta),\left(w^{b}+\iota(\theta)+\rho g\right) \cdot(1-q)\right\}$, where $\iota(\cdot)$ takes value $\theta$ for motivated agents and zero otherwise. To prevent an agent from being corrupt the wage in the bureaucracy must satisfy

$$
w^{b} \geq \chi \rho g-\iota(\theta)
$$

\footnotetext{
${ }^{7}$ In Francois (2000) the non pecuniary benefits are an increasing function of the provided level of public service. All the results would be preserved if the private benefits were endogenous and increasing in the level of public good provision. Any mechanism that implies a higher level of motivation in a good equilibrium would be an additional source for multiple equilibira. By omitting these forces, the model more transparently underlines a different source for multiple equilibria.
} 
with $\chi=\frac{1-q}{q}$. The rents that one can extract through corruption are given by $\widetilde{g}=g(1-q)$. These rents can be endogeneized through internal or external mechanisms without affecting the main results. For instance, the probability of being caught taking bribes could depend on the motivation of supervisors, or the amount of money that one can divert could depend on the level of economic development of the country.

It should be clear from the model sketched above that the wage paid in the public sector could be made endogenous by solving the agency problem in the government for a given distribution of bargaining power between different levels of the public sector hierarchy. Depending on the resources available to the government, the valuation of the project by the government, and the amount of rents that superior liars in the government would retain, equilibrium payoffs from honesty and corruption would be obtained. The only important requirement for the results to hold is that, for some range of the above parameters (rents, etc... ) the equilibrium behavior and payoffs in the public sector of motivated and non motivated agents would be different. This reduced form specification delivers the main intuition in a more transparent way, remaining silent about the political economy mechanism beyond the determination of public sector wages and rent sharing, whose analysis deserves separate treatment. 
Depending on the utility $U_{p}(G)$ that workers get in the private sector, a pooling $\left(V^{b}\left(w^{b}, 0\right)>U_{p}(G)\right)$ or a separating $\left(V^{b}\left(w^{b}, 0\right) \leq U_{p}(G)\right)$ equilibrium will arise. Let the public good provided $G(x)$ be an increasing function of $x$, the proportion of successful projects realized in the public sector. Depending on the selection of types and their compensation in the public sector, the proportion of corrupt agents will be equal to either zero, $1-\alpha$ or one. The bureaucracy could be composed of only honest agents producing a public good $G\left(p_{p}\right)=G_{h}$. We could then have a bureaucracy with honest motivated and corrupt non motivated agents, respectively in proportion $\alpha$ and $1-\alpha$, producing a public $\operatorname{good} G\left(\widetilde{p}=\alpha p_{p}+\frac{1}{2}(1-\alpha)\right)=G_{m}$, and lastly a public sector in which everybody is corrupt, producing a public good equal to $G\left(\frac{1}{2}\right)=G_{l}$. Clearly $G_{h}>G_{m}>G_{l}$.

I now turn to the private sector. Firms in the private sector hire $n$ workers each running a project whose payoffs are independently distributed. The structure of the agency problem is identical to that specified in the section above. In particular a worker in the private sector earns a utility equal to $U_{p}(G)=\max \left\{p_{p} y_{p}(G)-e_{p}-\pi_{p} ; \frac{1}{2} y_{p}(G)-\pi_{p}\right\}$. The utility in the private sector is thus increasing in $G$ and decreasing in $\pi_{p}$, which is a measure of bargaining power for entrepreneurs. Given that $p_{p}>\frac{1}{2}$, we have that effort will be exerted in the private sector only if $y_{p}(G)$ is sufficiently high. The 
bargaining power of firms, as summarized by $\pi_{p}$, affects the effort decision and, most importantly, the selection of agents across the two sectors: raising $\pi_{p}$ makes the public sector relatively more attractive.

\subsection{Results}

The model above, in having a fixed amount of places in the public sector equal to $b$, necessarily entails some rationing. Hence the equilibrium payoffs of workers in the two sectors will generally not be equalized. While the case in which everybody prefers to work in the public sector does not represent a problem because of the rationing, it is in principle possible that nobody wants to work in the public sector. This case is ruled out by

\section{Assumption 1}

i) Assume $U_{p}\left(G_{h}\right)=p_{p} y_{p}(G)-e_{p}-\pi_{p} \leq w^{b}+\theta$.

ii) $\Delta p_{p} y_{p}\left(G_{l}\right) \geq \frac{\Delta p_{p} \pi_{p}}{p_{p}}+e_{p}$

Part i) says that even when the public sector is of very high quality, the payoffs in the private sector are such that motivated workers would prefer to go in the public sector. Without this assumption it could happen that nobody wants to work in the public sector. Either the wage in the public sector should be raised, or an alternative mechanism should be specified 
to ensure a well defined equilibrium. We omit this case from the analysis without affecting the main results and in order to present the main intuition and results in the neatest possible way. Part ii) rules out the case in which workers do not exert effort in the private sector when the public sector is sufficiently inefficient, and further simplifies the analysis.

The following proposition completely characterizes the set of equilibria.

\section{Proposition 2}

$G=G_{l}$ is an equilibrium if $V(\rho \chi g-\theta, \theta) \geq \max \left\{U_{p}\left(G_{l}\right), w^{b}+\theta\right\}$ and

$w^{b} \in\left(\max \left\{0, V^{-1}\left(U_{p}\left(G_{l}\right), \theta\right)\right\}, \rho \chi g-\theta\right)$

$G=G_{m}$ is an equilibrium if $V(\rho \chi g, 0) \geq \max \left\{U_{p}\left(G_{m}\right), w^{b}\right\}$ and $w^{b} \in$ $\left[\max \left\{\rho \chi g-\theta, V^{-1}\left(U_{p}\left(G_{m}\right), 0\right)\right\}, \rho \chi g\right)$

$G=G_{h}$ is an equilibrium if $w^{b} \in[\rho \chi g, \infty)$ or if $V(\rho \chi g, 0)<U_{p}\left(G_{h}\right)$ and $w^{b} \in\left[\rho \chi g-\theta, \min \left\{V^{-1}\left(U_{p}\left(G_{h}\right), 0\right), \rho \chi g\right\}\right)^{8}$.

To prove the proposition we first note that, for a given wage in the public sector, the payoff of a motivated agent is always higher than the payoff for a non motivated agent. Moreover, if a motivated agent is corrupt, a non motivated agent will be corrupt, while the contrary is not necessarily true. $G_{l}$ can thus be obtained only if motivated agents are corrupt. $G_{m}$ can

\footnotetext{
${ }^{8}$ The last case is necessarly a pooling equilibrium.
} 
be obtained only with a pooling equilibrium in which only non motivated agents would be corrupt, while $G_{h}$ can be obtained with either a pooling or a separating equilibrium in which nobody is corrupt. The equilibrium correspondence is depicted in figure 1 . On the $x$-axis there is the wage in the public sector $w^{b}$, which is an exogenously given parameter. On the $y$-axis are reported the utility levels for workers in the public and private sector. In the private sector, depending on the efficiency of the public bureaucracy, these utilities are equal to $U_{p}\left(G_{i}\right)=U_{i}$, for $i \in\{H, M, L\}$. The thick lines show the equilibrium correspondence. When $w^{b}<\chi \rho g-\theta$, every public sector employee will be corrupt. This implies that the only possible realization of private sector utility is $U_{L}$, which is consistent with either a pooling or a separating equilibrium. When $w^{b} \in[\chi \rho g-\theta, \chi \rho g]$, motivated agents will be honest but non motivated agents will be corrupt. While $U_{M}$ is consistent only with a pooling equilibrium in this interval, $U_{H}$ will be consistent with a separating equilibrium in this interval. Lastly, if $w^{b} \geq \chi \rho g$, nobody will be corrupt, and the utility of workers in the private sector will be $U_{H}$. This figure immediately gives us

\section{Proposition 3}

When $w^{b} \in[\chi \rho g-\theta, \chi \rho g]$ multiple equilibria occur if $U_{p}\left(G_{m}\right) \leq V(\rho \chi g, 0)$ and $U_{p}\left(G_{h}\right) \geq V(\rho \chi g, \theta)$ for $w^{b} \in\left[\max \left\{\chi \rho g-\theta, V^{-1}\left(U_{M}, 0\right), V^{-1}\left(U_{H}, \theta\right)\right\}\right.$, 
$\left.\min \left\{\rho \chi g, V^{-1}\left(U_{M}, 0\right)\right\}\right]$

The same wage in the public sector, can be sufficient to deter corruption of motivated agents, but may not be enough to deter corruption of non motivated ones. When this is the case, the equilibrium level of $G$ is an increasing function of the utility that agents receive on the labor market. When the utility of working in the private sector is high enough, non motivated agents will not take a job in the public sector. On the other hand the equilibrium utility that workers receive on the private labor market is a weakly increasing function of $G$. The combination of these two increasing equilibrium relationships naturally leads to multiple equilibria. Therefore, a given level of the wage paid in the bureaucracy can be consistent with either a high, or a low wage in the private sector. Remember that the proportion of motivated agents $\alpha$ is bigger than the size of the bureaucracy $b$. The model says that it is not enough to have motivated agents in order to avoid corruption. Moreover it is not necessarily good to have cheap labor to hire in the public sector: cheap labor makes it more difficult to screen out non motivated and corrupt agents.

As noted in the previous section, when multiple equilibria exist they must be Pareto ranked. It is thus possible to reinterpret the multiplicity of equilibria as a form of coordination failure. Suppose that a non motivated 
agent thinks that other non motivated agents will go in the public sector looking for rents to extract through corruption. Given these beliefs, she will find it optimal to go in the public sector correctly anticipating that the wage in the private sector will be quite low. This reasoning is appealing because it relates the issue of corruption to the cultural situation of a given country, consistent with empirical evidence further discussed below.

To see why the two equilibria are necessarily Pareto Ranked, note that in a $G_{h}$ equilibrium workers in the private sector (motivated or not) are better off and motivated public servants are indifferent with respect to a $G_{m}$ equilibrium. The only issue is thus to compare the situation of corrupt public servants in the $G_{m}$ equilibrium with workers in the private sector in the $G_{h}$ one. By construction, in a $G_{h}$ equilibrium we have that $U_{p}\left(G_{h}\right)>V\left(w^{b}, 0\right)$, while in a $G_{m}$ equilibrium $V\left(w^{b}, 0\right)>U_{p}\left(G_{m}\right)$. The Pareto ranking thus comes from the definition of a good and a bad equilibrium in terms of separation versus pooling, and from the fact that the rents of being corrupt are identical in the two equilibria $\left(V\left(w^{b}, 0\right)\right.$ is constant across the two equilibria). The fact that the two equilibria are Pareto Ranked however implies that there are strong reasons for any political process to choose the high wage equilibrium.

Although very stylized, the public sector in this model combines two 
incentive problems: on the one hand paying a lower wage is used to attract only motivated agents (selection); on the other hand it is possible that some rents have to be paid in order to deter corruption and ex-post opportunistic behavior (moral hazard). The equilibrium interaction of the incentive compatibility and selection constraints, gives us the following

\section{Proposition 4}

When multiple equilibria exist, the level of corruption is not monotonic in the wage paid in the public sector, $w^{b}$, if $U_{p}\left(G_{h}\right) \leq \rho \chi g$.

The intuition for this result is as follow. Suppose the economy starts with a relatively low (but still higher than $\rho \chi g-\theta$ ) wage paid in the public sector. This wage is sufficiently high to deter corruption for motivated agents, and it is so low that it will not attract non motivated ones. The country will be characterized by a low level of corruption, despite the low wage in the public sector. Assume now that the wage in the bureaucracy rises for exogenous reasons. These additional rents will start attracting non motivated agents, but may well not be enough to deter their corruption. The level of corruption will jump to $1-\alpha$, the proportion of non motivated agents in the bureaucracy. Clearly further increases in the wage paid in the public sector will not change the selection of agents in the bureaucracy, but 
may lower the level of corruption, following the standard efficiency wage argument. In other terms, the endogenously determined outside option of the agents (the utility workers get in the private labor market) determines which constraints are binding when we change $w^{b}$.

\subsection{Occupational choice and wealth inequalities}

The model can be extended to consider a process of occupational choice to explore the effects of wealth inequalities. Assume wealth is distributed according to a continuous and strictly increasing cumulative function $F(a)$, $a \in[0, \infty)$. Each agent decides her occupation at the beginning of the period. She could become an entrepreneur, a bureaucrat or a worker in the private sector. A subsistence technology absorbs the excess labor supply. This technology is available to everybody and yields an individual return equal to $\underline{w}$. The set of occupations in the economy is therefore given by $o \in\{s, w, b, e\}$ (subsistence, workers, bureaucrats and entrepreneurs).

To become an entrepreneur an agent has to invest $k$ units of capital employing $n$ workers each running a different project. A successful project generates a return equal to $R+G$, where $G$ is as defined above. Credit markets are competitive, but not perfect. A borrower taking a loan of size $B$ will repay if and only if $B r \leq \lambda \pi$ where $r=1$ is the exogenously given 
interest rate, $\pi$ is endogenously determined profits and $\lambda$ is a constant related to the extent of credit market imperfections due to enforcement problems. Given that there is no need to invest more than $k$, an agent will be able to become entrepreneur if and only if she has wealth $a \geq a^{e}=k-\lambda \pi$.

As we have seen above, a critical variable is $\pi$, which summarizes how the bargaining power is distributed between firms and workers. Define $L^{d}$ and $L^{s}$ as the labor demand and supply respectively. Here, for simplicity, I assume the following bargaining power rule:

\section{Assumption 2}

i) The agents on the short side of the market get all the surplus from the relationship

ii) Conditional on application, the probability of getting a job in the public sector is independent of wealth.

Given a fixed coefficient technology, part i) simplifies the definition of equilibrium. Part ii) simplifies the analysis and is further discussed below. The simple bargaining power rule in assumption 2 implies

\section{Lemma 2}

Fix $G$, then the equilibrium on the private labor market is unique and it is characterized by $\pi^{*}$ such that $\pi^{*}=p_{p} y_{p}(G)-e_{p}-\pi^{*}$ if $G \geq G^{*}$, or $\pi^{+}$ 
such that $p_{p} y_{p}(G)-e_{p}-\pi^{+}=\underline{w}$ otherwise. $G^{*}$ is such that $\frac{n}{n+1}=F\left(k-\lambda \pi^{*}\right)$

A more efficient bureaucracy increases the returns of being entrepreneurs. More projects can be financed and this increases the aggregate labor demand. Fixing the level of public good at $G$, it is not possible to have multiple equilibria. Once again, this lemma makes clear that multiple equilibria arise along the $w^{b}$ dimension and come directly from the (general) equilibrium interaction between the public and the private sectors. I will not provide a characterization of the equilibrium correspondence since the extension remains very similar to the model analyzed above. The effects of wealth inequalities are analyzed in the following proposition.

\section{Proposition 5}

Assume $G_{h}>G^{*}>G_{l}$ and take first order stochastic dominance as a summary measure of inequalities in wealth distribution. Then

i) $G^{*}$ is increasing in wealth inequalities.

ii) An increase in inequalities can expand the multiple equilibria region.

A very unequal country may suffer from a lack of people having enough wealth to become entrepreneurs, and will thus tend to have lower wages in the private sector ${ }^{9}$. It will be more difficult to screen applicants for pub-

\footnotetext{
${ }^{9}$ See e.g. Banerjee and Newman (1993) and Ghatak and Joung (2002)
} 
lic office positions, and thus extreme inequalities will reinforce the perverse mechanism explored above. If, for historical or cultural reasons, potential entrepreneurs have on average higher public service motivation, or better opportunities to extracting rents from corruption in the public sector, the good equilibrium could be destroyed. This perverse effect is effectively equivalent to one in which richer classes are favored in the rationing process that shapes entry in the bureaucracy, or in which there are strong social stigma against entrepreneurship. Similar considerations are reported in Acemoglu (1995) and Baumol (1990).

\subsection{Motivated supervisors and endogenous rents}

Assume that the bureaucracy is composed by a continuum of agencies, and that each agency is composed by a large number of hierarchies. Civil servants in the bureaucracy are divided into two tasks: agents and supervisors. I assume for simplicity that each agent is matched with a supervisor. The agent now controls the amount of resources $g$ necessary to carry out the production of the public good. The supervisor has to exert some effort, which is non observable by third parties, in order to monitor the possible misuse of resources in the lower level of the hierarchy. With an effort cost

of $\frac{q^{2}}{2 \zeta}$ the supervisor find out if the agent is corrupt with probability $q$. 
While the corruption of an agent is verifiable by a third party, I assume here for simplicity that the outcome of the project can not be contracted upon and that the supervisor has to be paid a fixed wage $w^{m 10}$. The agent receives as before a fixed wage $w^{b}$. Agents and supervisors are recruited from the same pool of applicants: workers in the private sector. No educational investment is required to become either supervisor or agent. With respect to the previous section I assume for the sake of simplicity that a motivated civil servant will enjoy the non monetary pay-off, $\theta>g$, if and only if the public project succeeds. The project succeeds if the agent does not misuse public resources or if, in the case of corruption, she is caught. A motivated agent thus, will never be corrupt. Once the recruitment process is completed, public servants are randomly assigned to an agency, they then observe the type of their colleagues within the agency, and they form supervisor-agent pairs. In equilibrium, these pairs maximize the surplus of workers within the agency.

\section{Lemma 3}

\footnotetext{
${ }^{10}$ Indeed the supervisor could be given some incentives by conditioning her payment on the report about corruption (which is verifiable). Relaxing this assumption would not change the main intuition of the analysis: all that is needed is that a motivated supervisor has more incentives to monitor, and that a non motivated supervisor allows some rents to the agent, which occurs when the Nash equilibrium is at a corner, i.e. if $\zeta$ is low enough. Moreover, the provision of incentives may become very costly if collusion is allowed between the supervisor and the agent.
} 
Public servants surplus within each agency is maximized with assortative matching, i.e. motivated supervisors monitor motivated agents and non motivated supervisors monitor non motivated agents.

Letting a non motivated supervisor monitor a motivated agent does not produce corruption, it would be therefore optimal to allocate the motivated supervisor to the monitoring of a non motivated agents. This negative sorting allocation has two costs from the point of view of the supervisor - agent pairs: assuming an interior solution for the Nash Equilibrium, the non motivated agents would randomize, choosing a probability of being corrupt strictly lower than one, i.e. she will be losing a rent equal to $g$. The motivated manager will, with strictly positive probability, lose the non monetary pay-off. Moreover she exert some monitoring effort, which is costly.

\section{Proposition 6}

When multiple equilibria exist, they are not necessarily Pareto Ranked.

The intuition for this result goes as follows. In the previous section, the rents that one can acquire through corruption are exogenously given (both $g$ and $q$ were exogenous). Clearly, by the very definition of a pooling and a separating equilibrium, nobody (not even corrupt agents) can be better off in the bad equilibrium than in the good one. Introducing this simple hierarchy 
allows the endogeneization of the probability of being caught $q$, determining the rents that one can extract through corruption. In particular in a good equilibrium, the bureaucracy will be composed by motivated agents that will have high incentives to monitor. Therefore, a non motivated agent has no incentives to work in an honest bureaucracy. In the pooling equilibrium on the other hand, the bureaucracy is populated with supervisors that are in the public sector just to earn a higher wage, and the pressure to punish corruption is lower, thus a non motivated agent will be willing to enter the public sector. The endogenously higher rents from corruption in the bad equilibrium more than compensate the increase in the wage in the private sector.

None of the modelling assumptions above is important to get the results: what is really needed is that motivated supervisors will have more incentives to monitor than non motivated supervisors, and that the presence of enough non motivated supervisors attracts non motivated agents into the public sector. Allowing for collusion ${ }^{11}$, could be a way of giving incentives even to non motivated supervisors to monitor. If they can extract some of the rents that an agent is getting out of corruption they will have incentives to monitor. In equilibrium, this will in turn reduce the probability that the

\footnotetext{
${ }^{11}$ I.e. the possibility that, once a supervisor discovers the corruption of the agent, she can ask bribes, extracting at least a part of the rents from corruption.
} 
agent itself is corrupt. On the other hand allowing for collusion spreads the rents of corruption on multiple levels of the hierarchy making screening even more difficult. Again, a trade off between the provision of incentives on the job and selection is obtained.

The recruitment processes at different levels of the hierarchy are inherently linked. It is in fact the presence of (enough) non motivated supervisors that creates the rents attracting non motivated agents and causes corruption. This top-down mechanism, can be coupled by a bottom-up dynamic in the case in which the bureaucratic procedures allow for collusion: in this case, the presence of corrupt agents at lower levels creates rents for the supervisors. This implies that reforms at specific levels of the hierarchy can have important effects on the whole bureaucracy. For instance, targeting the recruitment of motivated supervisors can be a relatively cheap way of improving the performance of the entire public sector. The fact that in the model supervisors and agents are selected from the same pool, prevents us from properly comparing wage compression in the public and in the private sector. However, the fact that having motivated agents at the top of the bureaucratic hierarchy is particularly important suggests that wages at the top of the hierarchy should be lower (with respect to their counterparts in the private sector) than at the bottom. This is consistent with strong evi- 
dence of wage compression in the public sectors in developed and developing countries around the world.

More needs to be done on the analysis of the organizational forms of the public sector in the different equilibria of the model. In particular, it may be interesting to analyze the trade off between fostering motivation by delegating authority and controlling corruption by retaining formal authority at higher level of the public sector hierarchy. The analysis of the optimal degree of delegation can then be thought as a way of endogeneizing $\theta$.

\section{Discussion}

The equilibrium correspondence in the model is determined with respect to $w^{b}$. Are the main results of the model robust to endogeneizing $w^{b}$ through political economy mechanisms ? Multiple equilibria exist when the ratio of the values of a career in the private and public sector is close to one. It is likely that wages in the public sector will fall in this range even after controlling for political economy considerations. Wages in the public sector cannot be much higher than the highest possible wage in the private sector: the wage bill for the public bureaucracy would be too high, and taxpayers will not support it. Wages in the public bureaucracy may be very low instead 
generating endemic corruption, but this is unlikely to be a best response for many political regimes. Moreover, as emphasized in Borland and Gregory (1999) it is not clear which political economy mechanism determines public sector wages. To focus on the precise economic mechanism described in the paper, the model is silent about these aspects.

An important exogenous parameter is $\widetilde{g}=g(1-q)$, the rent that it is possible to acquire through corruption. While internal factors affecting $\widetilde{g}$ have been discussed in the previous section, general equilibrium factors will likely have an ambiguous effect, and are reasonably omitted here ${ }^{12}$.

Lastly, our results importantly depend on the exogeneity of $b$. In a sense the results are striking exactly if one neglects any kind of clienteralism that raises $b$ : a public sector recruiting workers for the pure sake of expanding political support will not recruit motivated agents only. The model says that having enough motivated agents in the economy is not enough to ensure a good bureaucracy in equilibrium. While a benevolent government may have an incentive to increase $b$ in order to reduce the labor supply and increase wages in the private sector, to facilitate screening, a clear trade off arises with respect to $w^{b}$, which will have to be lower, encouraging corruption and

\footnotetext{
${ }^{12}$ Acemoglu and Verdier (2000), for instance, relate the amount of money a bureaucrat can control to the level of economic development. Although $g$ could be increasing in $w$ or $\pi(\cdot)$ (a richer private sector representing a bigger temptation), $q$ is likely to increase also with the level of development. The net effects on $\widetilde{g}=g(1-q)$ are thus ambiguous.
} 
possibly reducing motivation ${ }^{13}$.

The main results of the model are ( i) the existence of multiple equilibria even for small variations in the level of the public sector wage premium, ii) the non monotonic relationship between public service compensation and corruption, and iii) the role of wealth inequalities in exacerbating corruption by reducing private sector wages) are broadly consistent with the existing empirical evidence.

The existence of multiple equilibria suggests that culture, through its effects on the expectations of individuals, may be an important determinant of corruption. Tresiman (2000) finds that history matters for corruption more than the current economic and political situation. He reports that "long lived aspects of countries' cultural or institutional traditions affect the level of perceived corruption more significantly than current state policies". Among the variables determining this "tenacity of the past" (exposure to) democracy and colonial origins seems to be the most important.

Treisman (2000) is cautious in reporting the negative impact that public sector wages have on corruption, because of endogeneity problems. Panizza (2001), Evans and Rauch (2001) and Van Rijckeghem and Weder (1997)

\footnotetext{
${ }^{13}$ Strong empirical evidence exists on the negative correlation between public sector wages and employment for developing countries (see e.g. Panizza (2000) and SchiavoCampo et al. (1997)).
} 
do not find that higher wages are associated with lower corruption. While an endogeneity problem exists (corrupt politicians will tend to set higher public sector wages), this evidence is consistent with our results on the non monotonic relationship between corruption and public sector wages.

The results in Panizza (2001) on Latin America, seem to suggest that inequalities may indeed exacerbate corruption: in this notoriously unequal region, a public sector wage premium is often observed associated with high levels of corruption. Treisman (2000) finds that, without controlling for economic development, Latin America seems indeed to have a higher degree of perceived corruption than what is predicted by other variables. SchiavoCampo et al.(1996) report evidence on the same lines. The recent successful experiences of some East Asian countries in reducing corruption (e.g. Thailand), may have been facilitated by a relative equality in the distribution of earnings, wealth, and opportunities. Lastly, in assessing the role of economic development in determining corruption, one has to pay attention to the reverse causality: corruption negatively affects development and growth.

The model identifies a precise mechanism (selection of public servant) through which low economic development feeds back into poor government quality and high corruption. Testing this mechanism through the estimation of a structural model awaits future research. 


\section{Conclusions}

This paper, after presenting a general mechanism producing multiple equilibria through the selection of heterogeneous individuals into different occupations, presents a model applying this mechanism to the analysis of the relationship between public sector motivation and development. The main results are i) multiple equilibria can exist for a given level of compensation in the public sector, ii) the relationship between public sector compensation and corruption may be non monotonic and iii) inequalities in wealth distribution tend to reinforce the persistence of corruption. These results are broadly supported by existing empirical evidence. The main policy implications are that it may not be sufficient to have a class of motivated agents willing to work in the public sector to escape corruption and underdevelopment. Moreover, cheap labor to hire in the bureaucracy, may indeed be a further cause, and not only a consequence, of corruption. The model thus identifies a precise channel through which the level of development is an endogenous variable in the cross country regressions explaining the quality of governance and corruption.

The model is simple, and it could be extended in many interesting directions. The analysis of the relationship between bureaucratic structures and organizational form of firms in developing countries seems to be particularly 
promising. Moreover a more complete theory must account for heterogeneity in talent among workers. Introducing some form of heterogeneity in workers tasks and wages would permit a detailed analysis of important institutional arrangements, such as the extent of wage compression, the modes of recruitment and the shape of career profiles in the two sectors. We leave the exploration of the equilibrium interplay of incentives between the private and public sector for future research.

\section{References}

[1] Acemoglu, D. (1995), Reward Structures and the Allocation of Talent, European Economic Review, 39, 17-33.

[2] Acemoglu, D. and T. Verdier (1998), Property Rights, Corruption and the Allocation of Talent: A General Equilibrium Approach, Economic Journal, 108, 1381-1403.

[3] Acemoglu, D. and T. Verdier (2000), The Choice Between Market Failures and Corruption, American Economic Review, 90, 194-211.

[4] Aghion, P. and J. Tirole (1997) Formal and Real Authority in Organizations, Journal of Political Economy, 105, 1-29. 
[5] Amsden, A. (1989) Asia's Next Giant: South Korea and Late Industrialization, Oxford University Press, New York.

[6] Banerjee, A. and A. Newman (1993) Occupational Choice and the Process of Economic Development, Journal of Political Economy, 101, 274-298.

[7] Bardhan, P. (1997) Corruption and Development: A Review of Issues, Journal of Economic Literature, Vol. XXXV, n $3.1320-1346.98$ (5), 893921

[8] Baumol (1990) Entrepreneurship: Productive, Unproductive and Destructive, Journal of Political Economy, 98, 893-921.

[9] Besley, T. and M. Ghatak (2003) Competition and Incentives with Motivated Agents, mimeo LSE, May 2003.

[10] Evans, P. (1998), Embedded Autonomy: States and Industrial Transformation, Princeton University Press.

[11] Evans, P. and P. Rauch (1999) Bureaucracy and Growth: a CrossNational Analysis of the Effects of "Weberian" State Structures on Economic Growth, American Sociological Review, in press. 
[12] Evans, P. and P. Rauch (2000) Bureaucratic Structure and Bureaucratic Performance in Less Developed Countries, Journal of Public Economics, $75,49-71$.

[13] Francois, P. (2000) Public Service Motivation as an Argument for Government Provision, Journal of Public Economics, Vol. 78, n 3, 275-300.

[14] Ghatak,M. et al. (2003) Credit Rationing, Wealth Inequality and Allocation of Talent, mimeo LSE, October 2002.

[15] Ghatak,M and N-H. Jiang (2002) A simple model of Inequality, Occupational Choice and Development, Journal of Development Economics, Vol. 69, No. 1, October 2002

[16] Gregory, R.and J. Borland (1999) Recent Developments in Public Sector Labor Markets, in Ashenfelter, O. and D. Card Eds. Handbook of Labor Economics, Vol. 3A, North-Holland Elsevier Press.

[17] Hart, O. and B. Holmstrom (2003) A Theory of Firm Scope, mimeo.

[18] Mauro, P. (1995) Corruption and Growth, Quarterly Journal of Economics, 110 (3), 681-712.

[19] Panizza, U. (2000) The Strange Case of the Public Sector Wage Premium: Evidence from Latin America, mimeo. 
[20] Rainey, H.G. and P. Steinbauer (1999) Galloping Elephants, Journal of Public Administration Research and Theory, 9 (1), 1-32.

[21] Schiavo-Campo, S. et al. (1997), An International Statistical Survey of Government Employment and Wages, WorldBank PRWP 1806, Whashington, DC.

[22] Treisman, D. (2000) The Causes of Corruption: a Cross-National Study, Journal of Public Economics, Vol. 76, n 3, 399-458.

[23] Van Rijckeghem, K. and B. Weder (1996) Corruption and the Rate of Temptation: Do Low Wages in the Civil Service Cause Corruption ? mimeo World Bank.

[24] Wade, R. (1990) Governing the Market: Economic Theory and the Role of Government in East Asian Industrialization, Princeton University Press.

[25] Wilson, J. (1989) Bureaucracy: What Government Agencies Do and Why They Do it, New York, Basic Books.

[26] World Bank (1993) The East Asian Miracle: Economic Growth and Public Policy, Oxford University Press, New York.

[27] World Bank (1997, 2002) World Development Report. 


\section{Appendix}

\section{Proof of Lemma 1}

We look for the contract that maximizes the utility of the agent. Denoting $w_{h, i}$ and $w_{l, i}$ the wages paid in case of failure and success in sector $i$, the contract will implement high effort $e_{i}$ if and only if $p_{i} w_{h, i}+\left(1-p_{i}\right) w_{l, i}-e_{H, i} \geq \frac{1}{2} w_{h, i}+$ $\frac{1}{2} w_{l, i}-e_{L, i}$ which is equivalent to $w_{h, i}-w_{l, i} \geq \frac{e_{H, i}-e_{L, i}}{p_{i}-\frac{1}{2}}=\frac{e_{i}}{\Delta p_{i}}$ (IC).

The contract must also yield a profit of at least $\pi_{i} \geq 0$ to the principals, i.e. it must satisfy $p_{i}\left(y_{i}\left(e_{j}\right)-w_{h, i}\right)-\left(1-p_{i}\right) w_{l, i} \geq \pi_{i}(\mathrm{ZP})$.

\section{Claim}

The ZP-constraint will be binding

Suppose not. Then it is possible to increase $w_{k, i}$, for $k=h, l$, while still satisfying the IC-constraint, increasing the utility of the agent, while still satisfying the ZP-constraint I|

Given risk neutrality, there will typically be an infinite number of contracts solving the problem, i.e. giving the same level of utility to the agent. A candidate solution is given by the contract on the intersection of $Z P$ and $I C$ constraints, provided it satisfies the limited liability constraints. This contract is given by $w_{h, i}=$

$\frac{\left(1-p_{i}\right)}{\Delta p_{i}} e_{i}+p_{i} y_{i}\left(n_{j}\right)-\pi_{i}$ and $w_{l, i}=-\frac{p_{i}}{\Delta p_{i}} e_{i}+p_{i} y_{i}\left(n_{j}\right)-\pi_{i}$, if $\pi_{i} \leq p_{i}\left(y_{i}-\frac{e_{i}}{\Delta p_{i}}\right)$, 
otherwise it is not possible to satisfy $L L C, Z P$ and $I C$, and the only implementable contract entails a low effort. Any contract implementing high effort gives a utility equal to $U_{i, h}=p_{i} y_{i}\left(n_{j}\right)-\pi_{i}-e_{i}$ to the agent.

The contracts implementing the low level of effort do not need to satisfy the $I C$ constraint, and will satisfy the $Z P$ constraint with equality. The contract giving no incentives at all, i.e. $w_{h, i}=w_{l, i}=w$ belongs to the this set of contracts and, using the $Z P$, gives utility equal to $U_{i, l}=\frac{1}{2} y_{i}\left(n_{j}\right)-\pi_{i}$.

Lastly, comparing $U_{i, l}$ and $U_{i, h}$ and rearranging terms we obtain $U_{i, h} \geq U_{i, l}$ if and only if $\Delta p_{i} y_{i}\left(n_{j}\right) \geq e_{i}$. This condition is weaker than $\pi_{i} \leq p_{i}\left(y_{i}-\frac{e_{i}}{\Delta p_{i}}\right)$ if $\pi_{i} \geq 0$

\section{Proof of Proposition 1}

When $e_{1}>\Delta p_{1}\left(y_{1}-\frac{\pi_{1}}{p_{1}}\right) \geq e_{1}-\theta, \theta-$ type takes action $e_{H}$ succeeding with probability $p_{1}$, and $0-$ type takes action $e_{L}$ succeeding with probability $\frac{1}{2}$. If $p_{1} y_{1}-e_{1}-\pi_{1}+\theta>p_{2} y_{2}\left(p_{1}\right)-e_{2}, \theta-$ type goes to sector 1 , even when the proportion of successes in sector 1 is $p_{1}$. When $p_{2} y_{2}\left(p_{1}\right)-e_{2}>\frac{1}{2} y_{1}-\pi_{1}, 0-$ type goes to sector 2 if the proportion of successes in sector 1 is equal to $p_{1}$. Separation is thus an equilibrium.

$$
\text { If } \frac{1}{2} y_{1}-\pi_{1}>p_{2} y_{2}\left(\alpha p_{1}+\frac{1}{2}(1-\alpha)\right)-e_{2}, 0-t y p e \text { (and a fortiori } \theta-\text { type }
$$

) agents go to sector 1 with probability equal to one. The realized proportion of 
successes in sector 1 is equal to $\widehat{p}=\alpha p_{1}+\frac{1}{2}(1-\alpha)$. Pooling is thus an equilibrium.

The third equilibrium is characterized as follows. Let $\alpha$ be the proportion of $\theta-$ type in the population of mass one. Define $\widehat{\alpha}$ as the solution of $p_{2} y_{2}(\widehat{p})-e_{2}=$ $\frac{1}{2} y_{1}-\pi_{1}$ where $\widehat{p}=\widehat{\alpha} p_{1}+\frac{1}{2}(1-\widehat{\alpha}) \in\left(\frac{1}{2}, p_{1}\right), . y_{2}(\cdot)$ being strictly increasing and $p_{1}>\frac{1}{2}$, if $p_{2} y_{2}\left(\frac{1}{2}\right)-e_{2}<\frac{1}{2} y_{1}-\pi_{1}<p_{2} y_{2}\left(p_{1}\right)-e_{2}$ this solution exists, is unique and such that $\widehat{\alpha} \in(0,1)$. Let $0-$ type randomize between sector 1 and 2 with respective probabilities $\widetilde{\alpha}$ and $1-\widetilde{\alpha}$, with $\widetilde{\alpha}$ such that $1-\widehat{\alpha}=\frac{(1-\alpha) \widetilde{\alpha}}{\alpha+(1-\alpha) \widetilde{\alpha}}$. Than $\theta$-types going to sector 1 with probability 1, 0 -types going to sector 1 with probability $\widetilde{\alpha}$ is (semi-)pooling equilibrium. To see why this equilibrium is not stable, suppose that a small measure of 0 -type randomize with probability $\widetilde{\alpha}-\varepsilon, \varepsilon$ arbitrarily small but positive. Then the realized proportion of 0 -type in sector 1 will be $1-\widehat{\alpha}^{\prime}<1-\widehat{\alpha}$, implying $p_{2} y_{2}\left(\widehat{p}^{\prime}\right)-e_{2}>\frac{1}{2} y_{1}-\pi_{1}$ for $\widehat{p}^{\prime}=\widehat{\alpha}^{\prime} p_{1}+\frac{1}{2}\left(1-\widehat{\alpha}^{\prime}\right)$. But then all the other $0-$ type will find profitable to go in sector 2 with probability 1 , destroying the equilibrium.

Lastly note that none of the conditions above is mutually exclusive with the others

\section{Proof of Proposition 2}

Existence of a $G_{l}$-equilibrium if and only if $U_{p}\left(G_{l}\right)<V(\rho \chi g-\theta, \theta)$ 
Clearly this type of equilibrium only can occur if $w^{b} \in[0, \chi \rho g-\theta]$. Suppose instead $U_{p}\left(G_{l}\right) \geq V(\rho \chi g-\theta, \theta)$, then, if $w^{b} \in\left[0, U_{p}\left(G_{l}\right)-\theta\right)$ nobody wants to work in the public sector, and assumption 1 is violated.

Existence of a $G_{m}$-equilibrium if and only if $U_{p}\left(G_{m}\right)<V(\rho \chi g, 0)$

Clearly this type of equilibrium only can occur if $w^{b} \in[\chi \rho g-\theta, \chi \rho g]$. Suppose instead that $U_{p}\left(G_{m}\right)>V(\rho \chi g, 0)$. Then in the relevant interval separation must occur, and partial corruption is not realized.

Existence of a $G_{h^{-}}$separating equilibrium if and only if $U_{p}\left(G_{h}\right)>V(\rho \chi g-\theta, 0)$

Suppose instead that $U_{p}\left(G_{h}\right) \leq V(\rho \chi g-\theta, 0)$. Then for $w^{b} \in[0, \rho \chi g-\theta)$ a pooling or a separating equilibrium may occur, but every agent will be corrupt. If $w^{b} \in[\rho \chi g-\theta, \rho \chi g)$ then a pooling equilibrium must occur, with non motivated agents being corrupt. If $w^{b} \in[\chi g, \infty)$, clearly a good equilibrium will be obtained but it will not separate agents

\section{Proof of Proposition 3}

Clearly multiple equilibria are possible only for $w^{b} \in[\rho \chi g-\theta, \rho \chi g]$ (cfr. Proposition 1$)$. To see why multiple equilibria exist if $U_{p}\left(G_{h}\right)<\chi \rho g+\theta$, note that when a $G_{m}$-equilibrium exists, it will exists over a range $w^{b} \in\left(V^{-1}\left(U_{p}\left(G_{m}\right), 0\right), \chi \rho g\right)$. Call this set $E_{p}$. If $U_{p}\left(G_{h}\right) \geq \chi \rho g+\theta$ only a pooling equilibrium exists for $w^{b} \in\left[V^{-1}\left(U_{p}\left(G_{h}\right), \theta\right), \infty\right)$, where $V^{-1}\left(U_{p}\left(G_{h}\right), \theta\right)>\chi \rho g$. Call this set $E^{p}$. 
When $U_{p}\left(G_{h}\right)<\chi \rho g+\theta$ instead, $G_{h}$-separating equilibria exist for $w^{b} \in$ $\left(\max \left\{V^{-1}\left(U_{p}\left(G_{h}\right), \theta\right), \chi \rho g-\theta\right\}, V^{-1}\left(U_{p}\left(G_{h}\right), 0\right)\right)$. Call this set $E^{s}$. Then $E^{p} \cap$ $E_{p}=\emptyset$, while $E^{s} \cap E_{p}=M E, M E$ defined as $w^{b} \in\left[\max \left\{\chi \rho g-\theta, V^{-1}\left(U_{p}\left(G_{m}\right), 0\right)\right.\right.$ ,$\left.\left.V^{-1}\left(U_{p}\left(G_{h}\right), \theta\right)\right\}, \min \left\{\chi \rho g, V^{-1}\left(U_{p}\left(G_{m}\right), 0\right)\right\}\right]$

\section{Proof of Proposition 4}

Immediate from inspection of figure 1

Proof of Lemma 2

\section{Claim}

Labor demand is increasing in $G$.

Labor demand is given by $n(1-F(k-\lambda \pi))\left(1-\alpha+\alpha\left(1-\frac{b}{\alpha}\right)\right)$ if $\pi>$ $V\left(w^{b}, 0\right)$ and $n(1-F(k-\lambda \pi))\left(1-\frac{b}{\alpha}\right)$ otherwise. $L^{d}$ is thus unambiguously increasing in $\pi$. So that $\pi$ must be higher when entrepreneurs are on the long side of the market. When entrepreneurs are on the long side of the market, they always have the possibility of becoming workers, so that $\pi=U_{p}(G)$. This implies that $\pi^{*}=p_{p} y_{p}(G)-e_{p}-\pi^{*} . \pi^{*}$ is thus increasing in $G$. When entrepreneurs are on the short side it must be that they get all the surplus from the relationship, i.e. $U_{p}(G)=\underline{w}$, this implies $p_{p} y_{p}(G)-e_{p}-\pi^{*}=\underline{w}$, so that again $\pi^{*}$ is increasing in $G \|$ 
Given the claim, we have to find the value of $G$ such that $L^{d}=L^{s}$. Using assumption 1 part i) and assumption 2) part ii), we have that $G^{*}$ is defined as the solution to $n \cdot\left(1-F\left(k-\lambda \pi^{*}(G)\right)\right)\left(1-\alpha+\alpha\left(1-\frac{b}{\alpha}\right)\right)=F\left(k-\lambda \pi^{*}(G)\right)(1-$ $\left.\alpha+\alpha\left(1-\frac{b}{\alpha}\right)\right)$ when only motivated agents apply for the public sector, and to $n \cdot\left(1-F\left(k-\lambda \pi^{*}(G)\right)\right)(1-b)=F\left(k-\lambda \pi^{*}(G)\right)(1-b)$ when everybody applies for the public sector. When $V(\theta)>\pi_{p}>V(0)>\underline{w}$ however $L^{d}=$ $F\left(k-\lambda \pi^{*}(G)\right)(1-b)$ while $L^{s}=n \cdot\left(1-F\left(k-\lambda \pi^{*}(G)\right)\right)\left(1-\alpha+\alpha\left(1-\frac{b}{\alpha}\right)\right)$. This case is however incompatible with $L^{d}=L^{s}$, because $\pi_{p}>\underline{w}$

\section{Proof of Proposition 5}

i) $G^{*}$ being the solution to $F\left(k-\lambda \pi^{*}(G)\right)=\frac{n}{n+1}$, part i) comes from the claim in the proof of Lemma 2. ii) By inspection of figure 1 noting that an increase in inequality can reduce $U_{p}\left(G_{m}\right)$

\section{Proof of Lemma 3}

Let us denote $q_{j}^{+}(\iota(\theta))$ the monitoring effort of a manager $j \in\{0, \theta\}$ when she is matched with an agent of type $\iota(\theta) \in\{0, \theta\}$ in a positive assortative matching equilibrium; $q_{j}^{-}(\iota(\theta))$ will be the corresponding equilibrium monitoring effort in a negative sorting equilibrium.

Claim 
The surplus generated by positive assortative matching is $W^{+}=2\left(w^{s}+w^{b}+\right.$ $\theta)+\rho g$.

A motivated agent will never be corrupt, and thus the project will succeed with probability one. The motivated manager, observing that the agent is motivated, and therefore will never be corrupt, has no incentives to exert monitoring effort: $q_{\theta}^{+}(\theta)=0$. The surplus generated by a pair of motivated agents - supervisor is $w^{s}+w^{b}+2 \theta$. A non motivated supervisor will never have incentives to monitor: $q_{0}^{+}(0)=0$. Knowing this, a non motivated agent will be corrupt with probability one. A non motivated pair thus generates a surplus $w^{s}+w^{b}+\rho g$. Summing the surplus of the two pairs gives us $W^{+}=2\left(w^{s}+w^{b}+\theta\right)+\rho g \|$

\section{Claim}

The surplus generated by negative sorting is $W^{-}=2\left(w^{s}+w^{b}+\theta\right)-$ $\frac{1}{\zeta} \frac{\rho g}{w^{b}+\rho g}\left(1-\frac{1}{2} \frac{\rho g}{w^{b}+\rho g}\right)$

A motivated agent again will never be corrupt, thus the project is realized successfully with probability one. The non motivated supervisor does not exert any effort, and thus $q_{0}^{-}(\theta)=0$. The pair motivated agent - non motivated supervisor generates a surplus of $w^{s}+w^{b}+\theta$. The motivated supervisor has incentives to monitor, and, given the probability $c$ that the non motivated agent is corrupt, she will optimally set $q_{\theta}^{-}(0)=\zeta c \theta$. If $\zeta \theta>\frac{g}{g+w^{b}}$ the equilibrium will be in 
mixed strategy. It will thus be given by $q_{\theta}^{-}(0)=\frac{g}{w^{b}+g}$ and $c=\frac{g}{w^{b}+g} \frac{1}{\zeta \theta}$. The non motivated agent is randomizing, she is thus indifferent between being corrupt or not, her payoff is equal to $w^{b}$. The utility of the motivated supervisor will be $w^{m}+\theta-\frac{1}{\zeta} \frac{g}{w^{b}+g}\left(1-\frac{1}{2} \frac{g}{w^{b}+g}\right)$. The total surplus generated by negative sorting will be $W^{-}=2\left(w^{s}+w^{b}+\theta\right)-\frac{1}{\zeta} \frac{\rho g}{w^{b}+\rho g}\left(1-\frac{1}{2} \frac{\rho g}{w^{b}+\rho g}\right) \|$

Finally, note that $W^{+}-W^{-}=\rho g+\frac{1}{\zeta} \frac{\rho g}{w^{b}+\rho g}\left(1-\frac{1}{2} \frac{\rho g}{w^{b}+\rho g}\right)>0 \mathbf{\square}$.

\section{Proof of Proposition 6}

Assume that while applying to the public sector a worker does not know if she will be supervisor or agent. Conditional of being accepted in the public sector, the two events are realized with the same probability. The proof works with the same logic if the assigned task in the public sector is known to the worker before the application is done.

\section{Claim}

In the (semi-)pooling equilibrium non motivated agents earn $V\left(w^{b}, 0\right)=\frac{1}{2}\left(w^{b}+\rho g\right)+$ $\frac{1}{2} w^{s}$

Because of the assortative matching result supervisors never monitor: motivated supervisors are matched with motivated agents, therefore they do not need to monitor. Non-motivated supervisors have no incentives to monitor. In the pooling equilibria thus, non motivated agents are never caught and earn $w^{b}+\rho g$. Being $\frac{1}{2}$ the 
probability of being assigned a supervisory task, $V\left(w^{b}, 0\right)=\frac{1}{2}\left(w^{b}+\rho g\right)+\frac{1}{2} w^{s}$ $\|$

\section{Claim}

In a separating equilibrium non motivated agents would earn in the public sector $V\left(w^{b}, 0\right)=\frac{1}{2} w^{b}+\frac{1}{2} w^{s}$.

Consider a deviation by a small mass of measure $\varepsilon$ of non motivated agents. The probability that they will be agents and matched with a non motivated supervisor is arbitrarily close to zero. $V\left(w^{b}, 0\right)=\frac{1}{2} w^{b}+\frac{1}{2} w^{s} \|$

The result then follows by noting that the (semi-)pooling equilibrium is defined by $\frac{1}{2}\left(w^{b}+\rho g\right)+\frac{1}{2} w^{s}>U_{p}\left(G_{m}\right)$, while the separating one is given by $\frac{1}{2} w^{b}+$ $\frac{1}{2} w^{s}<U_{p}\left(G_{h}\right)$. These two conditions do not exclude the case $\frac{1}{2}\left(w^{b}+\rho g\right)+$ $\frac{1}{2} w^{s}>U_{p}\left(G_{h}\right)$ 


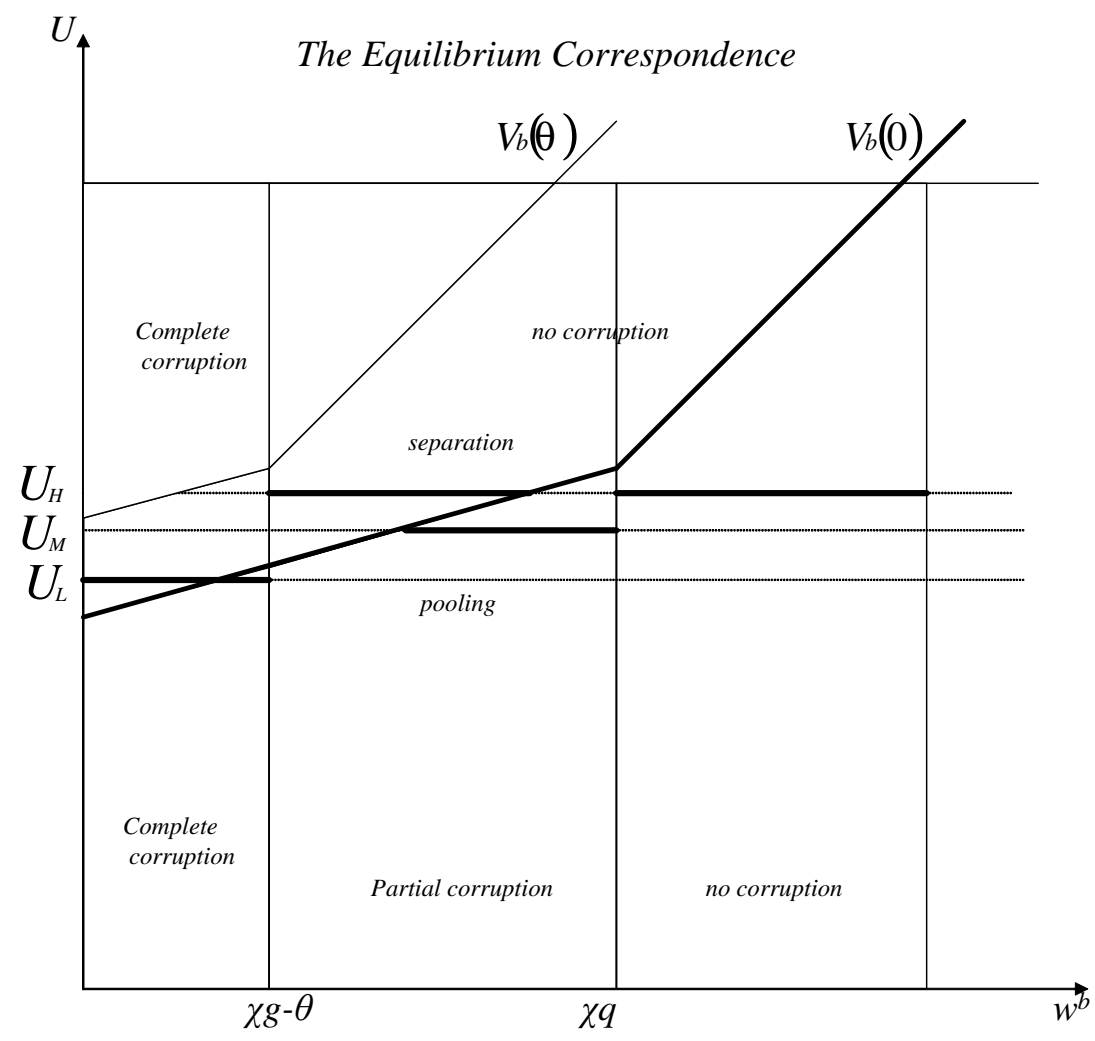

